\title{
Ventilation Mode and Epidural Bleeding in Microdiscectomy: Comparison of Two Ventilation Techniques
}

\author{
Ali Sefik KOPRULU ${ }^{1}$, Can CANATAN² ${ }^{2}$, Ali HASPOLAT³ ${ }^{3}$, Serdar KAHRAMAN ${ }^{4}$ \\ ${ }^{1}$ Yeni Yuzyil University, School of Medicine, Department of Anesthesiology and Reanimation, Istanbul, Turkey \\ ${ }^{2}$ Yeni Yuzyil University, Faculty of Health Sciences, Department of Health Management, Istanbul, Turkey \\ ${ }^{3}$ Universal Hospital Camlıca, Department of Anaesthesiology, İstanbul, Turkey \\ ${ }^{4}$ Yeni Yuzyil University, School of Medicine, Department of Neurosurgery, Istanbul, Turkey
}

\section{ABSTRACT}

AIM: Two different ventilation protocols during general anesthesia have been compared regarding their effects on amount of epidural bleeding during lumbar microdiscectomy in the prone position. Previous studies have not not revealed a relationship between ventilation mode and epidural bleeding in the prone position while measuring the intra-abdominal pressure (IAP) level.

MATERIAL and METHODS: This study was conducted on 40 American Society of Anesthesiologists (ASA) I and II patients that underwent a single level, unilateral lumbar microdiscectomy in the prone position. The anesthetic protocol was the same except the ventilation modes that were used in the study: (1) high volume-low frequency technique in group A, and (2) low volume-high frequency technique in group B. Pulmonary and hemodynamic parameters were noted. The patients also had urinary bladder catheter to measure the intra-abdominal pressure during surgery. Epidural bleeding was measured in every patient after microdiscectomy by using the aspiration volume. A convenience scale was used to assess the surgeon's satisfaction.

RESULTS: Although intra-abdominal pressure remained within normal ranges in both groups, peak and plateau pressures were slightly higher in group A. Mean epidural bleeding after ligamentum flavum resection was $43.9 \pm 11.82 \mathrm{ml}$ in group A, and $26.35 \pm$ $6.59 \mathrm{ml}$ in group B. The difference was statistically significant. Also the surgeon's satisfaction according to convenience scale was better in group $\mathrm{B}$.

CONCLUSION: Decreasing epidural venous engorgement depends on the ventilation technique and may lead to surgical convenience. It may be suggested that high frequency-low tidal volume ventilation during general anesthesia for lumbar microdiscectomy can be useful in minimizing epidural bleeding by using low peak and plateau pressure during surgery.

KEYWORDS: Lumbar microdiscectomy, Epidural bleeding, Lung protective ventilation

\section{INTRODUCTION}

$\mathrm{E}$ ven minor bleeding from epidural venous plexus can obstruct the surgeon's field of vision resulting in difficulties in microsurgical manipulation $(5,22)$. Apart from dissatisfaction of the surgeon, bleeding can cause unfavorable surgical outcomes and prolonged hospitalization $(8,11)$. Numerous studies have been performed on this issue, mainly regarding the surgical positioning of the patient in order to minimize the epidural bleeding of microdiscectomy (18).
The position of the patient may affect peak and plateau airway pressure due to the increase in intra-abdominal pressure that causes epidural venous engorgement via inferior caval system (12). Most studies have focused on the type of patient position but ignored ventilation modes for lumbar disc surgery. Not only the position of the patient but also differences in ventilation mode can shift peak and plateau airway pressures through both sides. Although the conventional high-volume anesthetic ventilation protocol is still widely using one side, low-volume 
ventilation as a lung-protective strategy is spreading rapidly in recent years among anesthesiologists, especially those who are working in intensive care units (9). However, studies examining the impact of the lung-protective strategy on surgical convenience are relatively rare.

Different tidal volumes and frequencies change peak and plateau airway pressures that may impact the amount of epidural bleeding during the microdiscectomy procedure. Our aim was to investigate how different ventilation protocols influence epidural bleeding and the surgeon's convenience during this procedure in a single-center prospective randomized study.

\section{- MATERIAL and METHODS}

This single-center prospective study was conducted on 40 patients. The hospital ethics committee approved the study (2012/An-006), and written informed consent was obtained from each patient. All patients were classified as status I or II according to the American Society of Anesthesiologists (ASA) classification. None of the patients had a history of previous abdominal or spinal surgery. All patients underwent a single level and unilateral lumbar microdiscectomy, with the diagnosis of L4-5 or L5-S1 disc herniation. All patients with a body mass index less than 30 were operated by the same experienced neurosurgeon (SK) who was blind to which ventilation mode was used to minimize the variability of such an evaluation and possible differences in surgical techniques. Patients with hypertension, cardiac disease, renal disease, liver disease and lung disease were not included in the study. Patients with bleeding tendency and those receiving anticoagulant or antiplatelet medication were excluded.

The same anesthetic protocol except the ventilation method was used in each patient. All patients received a $10 \mathrm{ml} . \mathrm{kg}^{-1}$ bolus of $0.9 \% \mathrm{NaCl}$ solution prior to induction, followed by $4 \mathrm{ml} . \mathrm{kg}^{-1}$.h continuous intravenous infusion. Anesthesia was induced by fentanyl (2 $\mu \mathrm{g} \cdot \mathrm{kg}^{-1}$ and propofol $\left(2 \mathrm{mg} \cdot \mathrm{kg}^{-1}\right)$, and endotracheal intubation was facilitated by rocuronium bromide $\left(0.5 \mathrm{mg} \cdot \mathrm{kg}^{-1}\right)$. Additional doses of rocuronium bromide $(0.15$ mg. $\mathrm{kg}^{-1}$ ) were administered in every 30 minutes. A mixture of $40-60 \% \mathrm{O}_{2}$-air, sevoflorane $1-1.5 \%$, and remifentanyl $\mathrm{HCl}$ infusion $\left(0.2 \mu \mathrm{g} \cdot \mathrm{kg}^{-1} \cdot \mathrm{min}\right)$ were used for the maintenance of anesthesia in both groups.

We used standard routine monitoring for this type of operation such as electrocardiogram with 3 derivations, non-invasive arterial pressure measurement, peripheral hemoglobin saturation and end tidal carbon dioxide. Heart rate and mean arterial pressure were noted at several stages including before and after anesthesia induction, before and after the beginning of surgery in the prone position, at the 45th minute of the operation, and at the end of the operation in both the prone and supine positions. These values were noted after extubation of the patient in the prone position. Oxygen saturation $\left(\mathrm{SpO}_{2}\right)$ was kept between $95 \%$ and $\% 100$, and end-tidal $\mathrm{CO}_{2}\left(\mathrm{ETCO}_{2}\right)$ was kept between 35 and $40 \mathrm{mmHg}$ in every patient and in each group. A rescue strategy that was stepwise increase of $\mathrm{F}_{\mathrm{i}} \mathrm{O}_{2}$ and PEEP was assigned for the patients in whom oxygen saturation fell to less than $95 \%$ without airway problems.
The ventilation mode was randomized by the anesthesiologist for each patient.

The patients were divided randomly into two groups according to the ventilation technique. There were 20 patients in each group. The ventilation technique used in group A was a highvolume low-frequency technique as in conventional practice. The respiratory rate was 8-10 per minute and the tidal volume was $10 \mathrm{ml} / \mathrm{kg}$. In group B, low volume with low PEEP and high frequency was used. Patients were ventilated with a tidal volume of $6 \mathrm{ml} / \mathrm{kg}$ and a respiratory rate of 16-18 breaths per minute. While zero external PEEP was applied in group $A$, the PEEP level was $3 \mathrm{~cm} \mathrm{H}_{2} \mathrm{O}$ in group $B$ as a lung-protective technique (7). Peak and plateau pressures were noted after anesthesia induction, before and after the beginning of the surgery in the prone position, at the 45th minute of the operation, and at the end of the operation in both the prone and supine positions.

A transurethral bladder catheter was placed before positioning the patient. Patients who had any contraindications to the placement of a transurethral bladder catheter or who had any difficulty during placement or in positioning of the catheter were excluded. Bladder pressure, as a technique for the measurement of intra-abdominal pressure, was noted within the same periods when peak and plateau pressures were measured. An additional measurement was also done after extubation in the supine position for bladder pressure. The technique used to measure intra-abdominal pressure was based on the fact that the wall of urinary bladder behaves as a passive diaphragm when bladder volume is between 50 and $100 \mathrm{ml}$ in an adult patient (21). As a measuring technique, the bladder was continuously emptied before measurements and the top of the symphysis pubis bone was used as the reference zero point. The measurement method of intraabdominal pressure was the same as described by Kron et al. (13). Sterile saline (50 cc) is injected into the empty bladder through an indwelling Foley catheter. The sterile tubing of the urinary drainage bag is cross-clamped just distal to the culture aspiration port. The end of the drainage bag tubing is connected to the indwelling Foley catheter. The clamp is released just enough to allow the tubing proximal to the clamp to allow fluid flow from the bladder and then reapplied. A 16-gauge needle is then used to connect the pressure transducer through the culture aspiration port of the tubing to the drainage bag. The mean pressure values were recorded at the end of the expiratory phase, avoiding the pressure changes during the ventilation phases.

All patients were operated in the prone position resting on silicone frame pads. A safe and stable positioning of the patient with good spinal lumbar flexion and minimal thoracic and abdominal compression by supporting with a cylindrical bolster from shoulder to iliac crest on both sides was arranged. Both anesthesiologist and neurosurgeon verified the correct position of the patient.

Epidural bleeding was determined accurately by measuring blood in the suction bottle that was used only for epidural level after resection of ligamentum flavum. The volume of irrigation solution used during microdiscectomy was subtracted from 
the volume in the suction bottle. Epidural bleeding was the concern of the study so only the bleeding after resection of ligamentum flavum was measured. At the end of the surgery, the surgeon was asked to rate the level of impairment of the visual field by blood, regarding the clarity of the field, on a convenience scale of 0 to 3 in which 0 was no impairment, 1 slightly impaired, 2, impaired, and 3 heavily impaired (21). The chi-square test was used for both gender and the convenience scale while the independent sample t-test was used for other parameters as statistical analysis and $p$ values less than 0.05 was accepted as statistically significant.

\section{RESULTS}

All patients were discharged without any surgical or anesthetic complications on the day after the operation. There were 9 females and 11 males in group $A(n=20)$ and 8 females and 12 males in group $B(n=20)$. The mean age was $42.9 \pm 9.72$ years in Group A and $43.35 \pm 8.29$ years in Group B. The Mean Body Mass Index (BMI) was $26.19 \pm 2.52$ in Group A and $26.62 \pm$ 6.59 in Group B. No significant intergroup difference was observed for age, sex or BMl. Mean operation time was 63.75 \pm 5.7 minutes in group $A$ and $62.95 \pm 4.62$ minutes in group $B$.
The difference was not statistically significant (Table I).

As a part of the study, oxygen saturation $\left(\mathrm{SpO}_{2}\right)$ and end-tidal $\mathrm{CO}_{2}\left(\mathrm{ETCO}_{2}\right)$ were kept between certain values $(95 \%$ to $100 \%$ for $\mathrm{SpO} 2$ and between 35 to $40 \mathrm{mmHg}$ for $\mathrm{ETCO}_{2}$ ). Only 2 patients needed a slight increment in $\mathrm{F}_{i} \mathrm{O}_{2}$ in group $\mathrm{B}$. Other ventilation parameters were not changed and the procedure was performed as it was planned before the operation. Hemodynamic parameters were compared statistically in both groups (Table II).

Intra-vesicular pressures are listed in Table III and the differences were not statistically significant. Both peak and plateau pressures were high in group $A$ and also in the prone position.

Mean epidural bleeding after ligamentum flavum resection was $43.9 \pm 11.82 \mathrm{ml}$ in Group A, and $26.35 \pm 6.59 \mathrm{ml}$ in Group B. The difference was statistically significant $(p<0.001)$. Table IV shows the results of convenience scale according to the assessment of the surgeon. The convenience scale was compared for both groups by using chi-square; the difference was statistically significant $(p=0.002, p<0.05)$.

Table I: Demographic Data

\begin{tabular}{|c|c|c|}
\hline & Group A & Group B \\
\hline \multirow[t]{2}{*}{ Gender (Female/Male) } & $9 \mathrm{~F} / 11 \mathrm{M}$ & $8 \mathrm{~F} / 12 \mathrm{M}$ \\
\hline & \multicolumn{2}{|c|}{ p: $0.749^{*}$} \\
\hline \multirow[t]{2}{*}{ Age (year) } & $42.9 \pm 9.72(29-63)$ & $43.35 \pm 8.29(29-56)$ \\
\hline & \multicolumn{2}{|c|}{$\mathrm{t}:-0.158$ / p: $0.876^{*}$} \\
\hline \multirow[t]{2}{*}{ Body Mass Index (BMI) } & $26.19 \pm 2.52(21.94-29.7)$ & $26.62 \pm 6.23(21.07-29.82)$ \\
\hline & \multicolumn{2}{|c|}{$\mathrm{t}:-0.540$ / p: $0.592^{*}$} \\
\hline \multirow[t]{2}{*}{ Operation time (min.) } & $63.75 \pm 5.7(55-73)$ & $62.95 \pm 4.62(52-71)$ \\
\hline & \multicolumn{2}{|c|}{ t: 0.488 p: $0.629^{\star}$} \\
\hline
\end{tabular}

(*) $p>0.05$ insignificant, $\left({ }^{* *}\right) \mathrm{p}<0.05$ significant.

Table II: Hemodynamic Parameters

\begin{tabular}{|c|c|c|c|c|c|c|c|c|}
\hline $\begin{array}{l}\text { Parameters } \\
\text { Groups }\end{array}$ & & Preop supine & After induct. & After prone & $\begin{array}{l}\text { After surg. } \\
\text { incision }\end{array}$ & $\begin{array}{l}45 \text { min. of } \\
\text { oper. }\end{array}$ & $\begin{array}{l}\text { Before extub. } \\
\text { in sup }\end{array}$ & After extub. \\
\hline \multirow{2}{*}{$\begin{array}{l}\text { HR } \\
\text { (beats/ min) }\end{array}$} & A & $84.35 \pm 9.8$ & $78.3 \pm 7.91$ & $77.7 \pm 6.66$ & $72.1 \pm 10.8$ & $69.35 \pm 9.64$ & $76.6 \pm 12.01$ & $81.35 \pm 8.2$ \\
\hline & B & $84.15 \pm 10.65$ & $77.95 \pm 6.46$ & $76.6 \pm 6.23$ & $71.9 \pm 8.2$ & $68.55 \pm 5.91$ & $76.95 \pm 4.21$ & $82.15 \pm 5.51$ \\
\hline t \& p values & & $\begin{array}{l}\mathrm{t}: 0.062 \\
\mathrm{p}: 0.951\end{array}$ & $\begin{array}{l}\mathrm{t}: 0.153 \\
\mathrm{p}: 0.879\end{array}$ & $\begin{array}{l}\mathrm{t}: 0.540 \\
\mathrm{p}: 0.593\end{array}$ & $\begin{array}{l}\mathrm{t}: 0.066 \\
\mathrm{p}: 0.948\end{array}$ & $\begin{array}{l}\mathrm{t}: 0.317 \\
\mathrm{p}: 0.753\end{array}$ & $\begin{array}{l}\mathrm{t}:-0.123 \\
\mathrm{p}: 0.903\end{array}$ & $\begin{array}{l}\mathrm{t}:-0.362 \\
\mathrm{p}: 0.719\end{array}$ \\
\hline \multirow{2}{*}{$\begin{array}{l}\text { MAP } \\
(\mathrm{mmHg})\end{array}$} & A & $95.75 \pm 9.69$ & $83.8 \pm 7.49$ & $83.55 \pm 9.01$ & $77.6 \pm 7.26$ & $77.7 \pm 7.71$ & $83.9 \pm 9.51$ & $92.2 \pm 7.59$ \\
\hline & B & $95.05 \pm 5.71$ & $84.85 \pm 5.67$ & $83.1 \pm 4.35$ & $77.11 \pm 6.68$ & $77.65 \pm 5.73$ & $86.55 \pm 7.84$ & $92.75 \pm 8.28$ \\
\hline t \& p values & & $\begin{array}{l}\text { t: } 0.278 \\
\text { p: } 0.782\end{array}$ & $\begin{array}{l}\mathrm{t}:-0.500 \\
\mathrm{p}: 0.620\end{array}$ & $\begin{array}{l}\mathrm{t}: 0.201 \\
\mathrm{p}: 0.842\end{array}$ & $\begin{array}{l}\text { t: } 0.227 \\
\text { p: } 0.822\end{array}$ & $\begin{array}{l}\mathrm{t}: 0.023 \\
\mathrm{p}: 0.982\end{array}$ & $\begin{array}{l}\text { t:-0.962 } \\
\text { p: } 0.342\end{array}$ & $\begin{array}{l}\mathrm{t}:-0.219 \\
\mathrm{p}: 0.828\end{array}$ \\
\hline
\end{tabular}

$p<0.05$ significant 
Koprulu AS. et al: Ventilation Mode and Epidural Bleeding

Table III: Bladder Pressure \& Pulmonary Parameters

\begin{tabular}{|c|c|c|c|c|c|c|c|}
\hline $\begin{array}{l}\text { Parameters } \\
\text { Groups }\end{array}$ & & After induct. & After prone & $\begin{array}{l}\text { After surg. } \\
\text { incision }\end{array}$ & $45 \mathrm{~min}$. of oper. & $\begin{array}{l}\text { Before extub. in } \\
\quad \text { sup }\end{array}$ & After extub. \\
\hline \multirow{2}{*}{$\begin{array}{l}\mathbf{P}_{\text {bladder }} \\
\text { (mmHg) }\end{array}$} & A & $7.85 \pm 2.6$ & $9.05 \pm 2.61$ & $9.4 \pm 2.21$ & $8.45 \pm 2.39$ & $7.75 \pm 1.94$ & $6.91 \pm 2.07$ \\
\hline & B & $7.81 \pm 2.61$ & $8.9 \pm 2.2$ & $9.4 \pm 1.47$ & $8.95 \pm 1.01$ & $8.05 \pm 1.43$ & $7.1 \pm 1.41$ \\
\hline t \& p values & & $\begin{array}{l}\mathrm{t}: 0.061 \\
\mathrm{p}: 0.952\end{array}$ & $\begin{array}{l}\mathrm{t}: 0.197 \\
\mathrm{p}: 0.845\end{array}$ & $\begin{array}{l}\mathrm{t}: 0.000 \\
\mathrm{p}: 1.000\end{array}$ & $\begin{array}{l}\mathrm{t}:-0.862 \\
\mathrm{p}: 0.394\end{array}$ & $\begin{array}{l}\mathrm{t}:-0.556 \\
\mathrm{p}: 0.582\end{array}$ & $\begin{array}{l}\text { t:-0.356 } \\
\text { p: } 0.723\end{array}$ \\
\hline \multirow{2}{*}{$\begin{array}{l}P_{\text {peak }} \\
\left(\mathrm{cm} \mathrm{H} H_{2}\right.\end{array}$} & A & $13.95 \pm 1.15$ & $17.5 \pm 1.15$ & $17.6 \pm 0.88$ & $17.25 \pm 0.85$ & $13.85 \pm 1.04$ & $x$ \\
\hline & B & $10.7 \pm 1.53$ & $14.3 \pm 1.26$ & $14.25 \pm 0.85$ & $14.3 \pm 0.66$ & $10.9 \pm 1.02$ & $x$ \\
\hline t \& p values & & $\begin{array}{c}\mathrm{t}: 7.619 \\
\mathrm{p}<0.001^{* *}\end{array}$ & $\begin{array}{c}\mathrm{t}: 8.396 \\
\mathrm{p}<0.001^{\star *}\end{array}$ & $\begin{array}{l}\mathrm{t}: 12.222 \\
\mathrm{p}<0.001^{\star *}\end{array}$ & $\begin{array}{l}\mathrm{t}: 12.274 \\
\mathrm{p}<0.001^{* *}\end{array}$ & $\begin{array}{c}\mathrm{t}: 9.053 \\
\mathrm{p}<0.001^{\star *}\end{array}$ & $x$ \\
\hline \multirow{2}{*}{$\begin{array}{l}P_{\text {plateau }} \\
\left(\mathrm{cm} \mathrm{H}_{2} \mathrm{O}\right)\end{array}$} & A & $12.05 \pm 1.28$ & $14.75 \pm 1.37$ & $14.46 \pm 1.27$ & $14.7 \pm 0.86$ & $12.15 \pm 0.99$ & $x$ \\
\hline & B & $8.8 \pm 1.67$ & $11.95 \pm 1.61$ & $11.8 \pm 1.6$ & $11.95 \pm 1.47$ & $9.05 \pm 1.46$ & $x$ \\
\hline t \& p values & & $\begin{array}{c}\mathrm{t}: 6.906 \\
\mathrm{p}<0.001^{\star \star}\end{array}$ & $\begin{array}{c}\text { t: } 5.931 \\
p<0.001^{\star *}\end{array}$ & $\begin{array}{c}\mathrm{t}: 6.221 \\
\mathrm{p}<0.001^{\star \star}\end{array}$ & $\begin{array}{c}\mathrm{t}: 7.219 \\
\mathrm{p}<0.001^{\star \star}\end{array}$ & $\begin{array}{c}\mathrm{t}: 9.162 \\
\mathrm{p}<0.001^{\star \star}\end{array}$ & $x$ \\
\hline
\end{tabular}

(*) $p<0.05$ significant, $\left(^{* \star}\right) p<0.001$ highly significant.

Table IV: Amount of Bleeding \& Convenience Scale

\begin{tabular}{lcc}
\hline & Group A & Group B \\
\hline Bleeding (cc) & $43.9 \pm 11.82$ & $26.35 \pm 6.59$ \\
\hline Convenience Scale & Group A & Group B \\
\hline 0 & $3(15 \%)$ & $10(50 \%)$ \\
\hline 1 & $2(10 \%)$ & $7(35 \% 9$ \\
\hline 2 & $6(30 \%)$ & $2(10 \%)$ \\
\hline 3 & $9(45 \%)$ & $1(5 \%)$ \\
\hline \multicolumn{3}{c}{ p: $0.002^{\star *}$} \\
\hline
\end{tabular}

$\left({ }^{\star}\right) p<0.001$ highly significant, $\left({ }^{* \star}\right) p<0.05$ significant

\section{DISCUSSION}

Epidural bleeding is an undesirable circumstance in spinal surgery and many attempts have been made to avoid it. Surgical experience, hemodynamic parameters, the patient's body mass index, the position of the patient, intra-abdominal pressure changes and finally airway pressure changes depending on position were expressed by researchers to reduce surgical bleeding $(2,5,10,12,16,21,27)$.

The epidural venous system, which has anatomically thin walls and a valveless communication with the inferior vena cava, is characterized by low blood pressure. Therefore any changes in intra-abdominal pressure are easily transmitted to the inferior vena cava, resulting in venous engorgement of epidural veins and increased epidural bleeding during surgery $(1,15)$.
Many of the papers on the subject have focused on patient positioning. The main focus has been minimizing the increase in intra-abdominal pressure by avoiding abdominal compression. Böstman et al. stated that intra-operative bleeding was significantly lower in patients positioned in a frame-supported kneeling position (2). Lee et al. showed that inferior vena cava pressure was significantly lower in patients positioned on a Relton-Hall frame (14). Sunden et al. introduced a new device called "vacuum pillow" and stated that intra-operative bleeding was significantly lower in patients positioned on this pillow (24). Other investigators have claimed that the effect of positioning on epidural bleeding is minimal under the usual conditions (21).

Although the main objective in all studies was to lower the intra-abdominal pressure in order to reduce intra-operative bleeding, statistical data was not consistently supportive. Böstman et al. demonstrated a minimization of bleeding in their study, but intra-abdominal pressures were not measured (2). Lee et al. showed a decrease in inferior vena cava pressure, but it was not correlated with intra-operative bleeding (14). Rigamonti et al. performed a study and stated that there was no correlation between intra-abdominal pressure and epidural bleeding (21). Han et al., in a study focusing on the effects of body mass index on intra-operative bleeding, stated that although the intra-abdominal pressure was slightly lower in the less bleeding group, the difference was not statistically significant (5).

The classic prone position resting on silicone frame pads, which is the most commonly used in these types of surgery, was used in our study in both groups. The position of the patient was checked by the same experienced neurosurgeon and anesthesiologist. Intra-abdominal pressure was also measured throughout the whole operation. Our findings showed a slight increase in abdominal pressure in the prone 
position but it always remained within normal limits. Although IAP was slightly lower in the less bleeding group (group B), no statistically significant changes were seen between the two groups, which is compatible with the literature (21).

It is widely known that not only the position of the patient but also ventilation modes can change airway pressures. Namely, mechanical ventilation with low tidal volumes in criticallyill patients has been considered a successful practice for a decade $(20,22)$. On the other hand, its role in general anesthesia is not well studied, and papers are emerging only recently $(4,6,9,23,26)$. One of the important parameters of increasing intra-abdominal pressure is airway pressures. Peak and plateau pressures are monitorized routinely by the anesthesiologist during the operation. These parameters could be used as an indicator of inappropriate positioning and also used for prediction of the epidural bleeding amount. The correlation between the amount of blood loss with peak and plateau airway pressure changes that occur after the patient was placed in a prone position was also shown by Koh et al. (12).

In this study, one of the groups has been ventilated with low tidal volumes $\left(\mathrm{V}_{\mathrm{T}} 6 \mathrm{ml} . \mathrm{kg}^{-1}\right)$ during general anesthesia, while the other one has been ventilated with relatively high tidal volumes (VT $10 \mathrm{ml}^{\mathrm{kg}} \mathrm{kg}^{-1}$ ) that are generally used in common practice. On the other hand, the PEEP levels that were used in our patients were relatively low similar to some authors that aimed lung protection $(3,7,25)$. Besides, our patient population had no major co-morbidity regarding age, pulmonary function and operation time. It is also accepted that the prone position can improve mechanical ventilation parameters in maintaining oxygen saturation $(19,20)$. Furthermore, some studies have shown that low VT and high PEEP mechanical ventilation as a lung protective strategy in common practice results in increased inflammation and ventilation-associated lung injury in normal lungs, contrary to expectations for lung protection $(7,25)$. Some other authors have claimed that the ventilation strategy has minimal impact on markers of systemic inflammation (17).

Our results have shown that the group receiving low tidal volumes during general anesthesia had a significantly less amount of epidural bleeding while there was no significant difference between the intra-abdominal pressures of the two groups. These findings are in agreement with some studies in the literature $(15,21)$. Although the main aim of this study was to improve the surgeon's satisfaction regarding epidural bleeding, there is no qualitative measurement method of the quality of microscopic exposure. However, there are some non-specific scales like the convenience scale that was used in our study (21). Apart from the amount of bleeding, the surgeon has stated that the comfort of the surgery was higher in the low tidal volume group. Particularly, less venous engorgement might lead to easier microsurgical manipulation than the other group from the surgeon's point of view. The importance of this subjective comment could be verified statistically by using convenience scale. In order to minimize the effect of surgical technique and experience differences in operations, we have worked with the same experienced neurosurgeon during the whole study. The same neurosurgeon who was blind about ventilation mode evaluated bleeding and surgical convenience. However, it must be remembered that the convenience scale that was used in our study has a limitation. "Single center" and "same neurosurgeon" were the other limitations of the study. Further consideration in multicentric model and definition of a more extensive scoring system regarding the quantitative assessment may be required.

Demographic data including body mass index and hemodynamic parameters showed no statistical difference between the groups. Previous studies have suggested that prone or somewhat position or frame was preferred by the surgeon equally affects epidural bleeding (16). Moreover, positioning of the patients and intra-abdominal pressure changes that might affect epidural bleeding were the same in our both groups.

The only variable with respect to epidural bleeding we had in this study was ventilation mode. The main question is that how this variable impacts epidural bleeding while all other parameters were in normal range and stable during surgery. There is no previously described valid method to measure epidural venous pressure directly. We think that the valveless and thin wall veins of the epidural area that has low venous pressure may easily reflect any changes of pressure in the inferior vena cava even if we could not determine this with any method as a result of the compensating mechanism due to the peak and plateau pressure effect on venous return.

Although these results are preliminary, it may be suggested that low tidal volume ventilation during general anesthesia for lumbar microdiscectomy is not only protective for the pulmonary system but might also be useful in minimizing epidural bleeding intra-operatively. On the other hand, surgical convenience seems to be better than in the high tidal volume group, although differences in the epidural bleeding amount were relatively small.

\section{- REFERENCES}

1. Batson OV: The function of vertebral veins and their role in the spread of metastases. Ann Surg 112: 138-149, 1940

2. Böstman O, Hyrkäs J, Hirvensalo E, Kallio E: Blood loss, operating time and positioning of the patient in lumbar disc surgery. Spine 15: 360-363, 1990

3. Cai H, Gong H, Zhang L, Wang Y, Tian Y: Effect of low tidal volume ventilation on atelectasis in patient during general anesthesia: A computed tomographic scan. J Clin Anesth 19: 125-129, 2007

4. Futier E, Constantin J M, Paugam-Burtz C, Pascal J, Eurin $M$, Neuschwander A, Marret E, Beaussier M, Gutton C, Lefrant JY, Allaouchiche B, Verzilli D, Leone M, De Jong A, Bazin JE, Pereira B, Jaber S; IMPROVE Study Group: A trial of intraoperative low-tidal-volume ventilation in abdominal surgery. N Eng J Med 5:428-437, 2013

5. Han IH, Son DW, Nam KH, Choi BK, Song GS: The effect of body mass index on intra-abdominal pressure and blood loss in lumbar spine surgery. J Korean Neurosurg Soc 51:81-85, 2012 
6. Hemmes SN, Serpa Neto A, Schultz MJ: Intraoperative ventilatory strategies to prevent postoperative pulmonary complications: A meta-analysis. Curr Opin Anaesthesiol 26: 126-133, 2013

7. Hong CM, Xu DZ, Lu Q, Cheng Y, Pisarenko V, Doucet D, Brown M, Aisner S, Zhang C, Deitch E, Delphin E: Low tidal volume and high positive end expiratory pressure mechanical ventilation results in increased inflammation and ventilatorassociated lung injury in normal lungs. Anesth Analg 6:16521660, 2010

8. Imagama S, Kawakami N, Tsuji T, Ohara T, Matsubara Y, Kanemura T, Goto M, Katayama Y, Ishiguro N: Perioperative complications and adverse events after lumbar spinal surgery: Evaluation of 1012 operations at a single center. J Orthop Sci 16: 510-515, 2011

9. Jaber S, Coisel Y, Chanques G, Futier E, Constantin JM, Michelet P, Beaussier M, Lefrant JY, Allaouchiche B, Capdevila $X$, Marret E: A multicentre observational study of intraoperative ventilator management during general anaesthesia: Tidal volumes and relation to body weight. Anaesthesia 67: 999-1008, 2012

10. Kakiuchi M: Reduction of blood loss during spinal surgery by epidural blockade under normotensive general anesthesia. Spine 8: 889-894, 1997

11. Karikari IO, Isaacs RE: Minimally invasive transforaminal lumbar interbody fusion: $A$ review of techniques and outcomes. Spine 35: 294-301, 2010

12. Koh JC, Lee JS, Han DW, Choi S, Chang CH: Increase in airway pressure resulting from prone position patient placing may predict intraoperative surgical blood loss. Spine 11: 678682, 2013

13. Kron JL, Harman PK, Nolan SP: The measurement of intraabdominal pressure as a criterion for abdominal reexploration. Ann Surg 199: 28-30, 1984

14. Lee TC, Yang LC, Chen HJ: Effect of patient position and hypotensive anesthesia on inferior vena caval pressure. Spine 23: 941-948, 1998

15. Mathai KM, Kang JD, Donaldson WF, Lee JY, Buffington CW: Prediction of blood loss during surgery on the lumbar spine with the patient supported prone on the Jackson table. Spine J 12:1103-1110, 2012

16. McNulty SE, Weiss J, Azad SS, Schaefer DM, Osterholm JL, Seltzer JL: The effect of the prone position on venous pressure and blood loss during lumbar laminectomy. J Clin Anesth 4: 220-225, 1992
17. Memtsoudis SG, Bombardieri AM, Ma Y, Girardi FP: The effect of low versus high tidal volume ventilation on inflammatory markers in healthy individuals undergoing posterior spine fusion in the prone position: A randomized controlled trial. J Clin Anesth 4:263-269, 2012

18. Park CK: The effect of patient positioning on intraabdominal pressure and blood loss in spinal surgery. Anesth Analg 91: 552-557, 2000

19. Petterson J, Ax M, Frey J, Sanchez-Crespo A, Lindahl SGE, Mure $M$ : Positive end-expiratory pressure redistributes regional blood flow and ventilation differently in supine and prone humans. Anesthesiology 113: 1361-1369, 2010

20. Prost ND, Dreyfuss D: How to prevent ventilator-induced lung injury. Minerva Anestesiol 9:1054-1066, 2012

21. Rigamonti A, Gemma M, Rocca A, Messina M, Bignami E, Beretta L: Prone versus knee-chest position for microdiscectomy: A prospective randomized study of intra-abdominal pressure and intraoperative bleeding. Spine 11: 1918-1923, 2005

22. Serpa Neto A, Cardoso SO, Manetta JA, Pereira VG, Espósito DC, Pasqualucci Mde O, Damasceno MC, Schultz MJ: Association between use of lungprotective ventilation with lower tidal volumes and clinical outcomes among patients without acute respiratory distress syndrome: A meta-analysis. JAMA 308: 1651-1659, 2012

23. Severgnini $P$, Selmo G, Lanza $C$, Chiesa A, Frigerio A, Bacuzzi A, Dionigi G, Novario R, Gregoretti C, de Abreu MG, Schultz MJ, Jaber S, Futier E, Chiaranda M, Pelosi P: Protective mechanical ventilation during general anesthesia for open abdominal surgery improves postoperative pulmonary function. Anesthesiology 118: 1307-1321, 2013

24. Sunden G, Walloe A, Wingstrand H: A new device to reduce intra-abdominal pressure during lumbar surgery. Spine 11: 635-636, 1986

25. The PROVE Network Investigators for the clinical trial network of the ESA, Hemmes SN, Gama de Abreu M, Pelosi P, Schultz MJ: High versus low positive end-expiratory pressure during general anaesthesia for open abdominal surgery (PROVHILO trial): A multicentre randomized controlled trial. Lancet 384(9942):495-503, 2014

26. Wrigge $\mathrm{H}$, Pelosi $\mathrm{P}$ : Tidal volumes in patients with normal lungs during general anesthesia; Lower the better? Anesthesiology 114: 1011-1013, 2011

27. Yilmaz C, Buyrukcu SO, Cansever T, Gulsen S, Altinors N, Caner $\mathrm{H}$ : Lumbar microdiscectomy with spinal anesthesia: Comparison of prone and knee-chest positions in means of hemodynamic and respiratory function. Spine 11:1176-1184, 2010 